Technological University Dublin

DƯBLIN

ARROW@TU Dublin

2007-01-01

\title{
Characteristics of Cooked Chickpeas and Soybeans during Combined Microwave-Convective Hot Air Drying
}

\author{
Aoife Gowen \\ University College Cork \\ Nissreen Abu-Ghannam \\ Technological University Dublin, nissreen.abughannam@tudublin.ie \\ Jesus Maria Frias \\ Technological University Dublin, Jesus.Frias@tudublin.ie
}

See next page for additional authors

Follow this and additional works at: https://arrow.tudublin.ie/schfsehart

Part of the Food Chemistry Commons, and the Food Processing Commons

\section{Recommended Citation}

Gowen, A. et al. (2007). Characteristics of cooked chickpeas and soybeans during combined microwave-convective hot air drying. Journal of Food Processing and Preservation, 31(4), 433-453. DOI: 10.1111/j.1745-4549.2007.00139.x

This Article is brought to you for free and open access by the School of Food Science and Environmental Health at ARROW@TU Dublin. It has been accepted for inclusion in Articles by an authorized administrator of ARROW@TU Dublin. For more information, please contact arrow.admin@tudublin.ie, aisling.coyne@tudublin.ie, gerard.connolly@tudublin.ie.

Funder: Irish government under Strand I of the National Development Plan

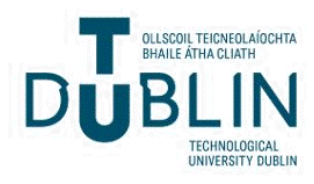




\section{Authors}

Aoife Gowen, Nissreen Abu-Ghannam, Jesus Maria Frias, and Jorge Oliveira

This article is available at ARROW@TU Dublin: https://arrow.tudublin.ie/schfsehart/53 


\title{
CHARACTERISTICS OF COOKED CHICKPEAS AND SOYBEANS DURING COMBINED MICROWAVE-CONVECTIVE HOT AIR DRYING
}

\author{
AOIFE A. GOWEN ${ }^{1,3}$, NISSREEN ABU-GHANNAM ${ }^{1}$, JESUS M. FRIAS ${ }^{1}$ and \\ JORGE C. OLIVEIRA ${ }^{2}$ \\ ${ }^{1}$ School of Food Science and Environmental Health \\ Dublin Institute of Technology \\ Dublin 1, Ireland \\ ${ }^{2}$ Department of Process Engineering \\ University College Cork \\ Cork, Ireland
}

Accepted for Publication April 9, 2007

\begin{abstract}
Moisture content, shrinkage, water activity $\left(\mathrm{A}_{w}\right)$, color and texture of cooked chickpeas and soybeans during convective, microwave and combined microwave-convective drying were studied. Combined drying was significantly $(\mathrm{P}<0.05)$ faster than either convective or microwave drying, and resulted in less shrinkage of the dehydrated product. Rapid burning occurred when samples were dried below a $\mathrm{A}_{w}$ of $0.27 \pm 0.07$ for chickpeas $(\mathrm{P}<0.05)$, and $0.13 \pm 0.04$ for soybeans $(\mathrm{P}<0.05)$. Both chickpeas and soybeans displayed a transitional behavior in texture when dried to a $\mathrm{A}_{w}$ below $0.40 \pm 0.10(\mathrm{P}<0.05)$ for chickpeas, and below $0.63 \pm 0.15(\mathrm{P}<0.05)$ for soybeans, when samples became brittle. Shelf stable dehydrated chickpea and soybean products with low water activity $\left(\mathrm{A}_{w}=0.35\right)$ and good visual quality could be obtained within 14 min of combination drying.
\end{abstract}

\section{PRACTICAL APPLICATIONS}

Simultaneous combination of microwave and air drying has been demonstrated as an economical method to produce highly rehydratable chickpea and soybean products in short processing times. The dehydrated products could potentially be developed as novel food products. For example, pregelatinized dehydrated legume products have potential commercial use, in

${ }^{3}$ Corresponding author. TEL: 00353-14024369; FAX: 00353-18788721; EMAIL: aoife.gowen@ dit.ie

Journal of Food Processing and Preservation 31 (2007) 433-453. All Rights Reserved.

(C) 2007, The Author(s)

Journal compilation (C) 2007, Blackwell Publishing 
their dried form, as healthy snack-foods. Appropriate scaling up of the dehydration processes described in this paper, in conjunction with extensive sensory analysis would be required to develop such products.

\section{INTRODUCTION}

Convective drying is a traditional method of food preservation, yet still of major importance in today's food industry (Krokida et al. 2003). With the advances of technology over the years, newer drying methods, such as microwave-, freeze- and vacuum-drying, have been developed, and have been combined with conventional drying processes to provide innovative techniques in dry food processing (Nijhuis et al. 1998; Vega-Mercado et al. 2001). Combining microwave energy with convective drying has delivered dramatic reductions in drying times (up to 90\%) for apples (Bilbao-Sainz et al. 2005), pasta (Berteli and Marsaioli 2005), kiwis (Maskan 2001), bananas (Maskan 2000), garlic cloves (Sharma and Prasad 2001) and mushrooms (Funebo and Ohlsson 1998), compared to convective drying alone.

Development of a dehydrated food product requires the consideration of a number of factors. From a producer's point of view, the main factors of interest are production costs, processing time, product shelf life and product quality. The choice of one particular drying method above another is dependent upon its ability to produce a shelf stable product, while optimizing quality and cost. In terms of producing a shelf stable product, primary concerns are microbial safety, color stability and prevention of deteriorative reactions during storage, such as lipid oxidation. The inter-related concepts of water activity and glass transition are commonly used by the industry as indicators of the stability of food products (Ratti 2001; Sablani et al. 2007).

Water activity $\left(A_{\mathrm{w}}\right)$ is a dimensionless measure of the free water in a food system, available to support biological and chemical reactions. During dehydration, the majority of free water contained in the food is removed, and $A_{\mathrm{w}}$ subsequently decreases, inhibiting the onset of undesirable reactions such as microbial growth. Consequently, reducing the water activity of a product is an important step in microbial control. It is generally accepted that for $A_{\mathrm{w}}<0.66$, there should be no microbial growth (Labuza 1980). Many other deteriorative reactions, such as lipid oxidation and browning are related to water activity. Lipid oxidation of foods is generally minimal for $A_{\mathrm{w}}$ between 0.3 and 0.5 (Troller 1989). Priestly et al. (1985) found that with a moisture range of 5-16\% (corresponding to $A_{\mathrm{w}}$ range $0.4-0.8$ ), soybeans vary little in vulnerability to lipid oxidation. Browning of foods during processing and storage is a major issue of concern for food producers. During dehydration, browning is dependent upon both water activity and drying temperature. 
Eichner et al. (1985) reported that although decreasing water activity controls food browning, reducing temperature during the final stages of drying is even more important. Labuza and Saltmarch (1981) found that browning rate during storage reaches a maximum in the 0.6-0.9 $A_{\mathrm{w}}$ range. Accordingly, drying food products to a final $A_{\mathrm{w}}$ level between 0.3 and 0.5 should ensure microbial safety, while preventing lipid oxidation and browning during storage.

Glass transition refers to the change in state of a solid matrix from the rubbery, amorphous state to the glassy, crystalline state. A glass transition temperature $\left(T_{\mathrm{g}}\right)$ can be associated with any particular food matrix at a constant moisture content, above which the food matrix enters the mobile rubbery state. Reducing moisture content generally raises $T_{\mathrm{g}}$ (Kasapis 2006); therefore drying foods to sufficiently low moisture contents can result in glassy, dry product. In the glassy state, molecular mobility is very low, and consequently the speed of deteriorative reactions is slow. Ling et al. (2005) found that color stability of pear slices could be conferred by drying them to a moisture content low enough such that glass transition occurred. Shrinkage during drying is also related to $T_{\mathrm{g}}$. Significant volume changes can only occur when a product is in the rubbery state, so that volume stability is achieved when the product encounters temperatures lower than $T_{\mathrm{g}}$ at any particular moisture content (Ratti 2001).

Dried legumes (known as pulses) are well known for their nutritional and functional value; however, they are underutilized in Europe because of the long soaking and cooking times they require (Schneider 2002). In the dry state, legumes have a low moisture content (9-10\%) and enjoy long shelf life. However, they necessitate long soaking and cooking times to make them edible. Drying of cooked chickpeas using a combination of microwave and convection air is a promising method, which could produce highly rehydratable products in short drying times (Gowen et al. 2006). In this study, dehydration of cooked chickpeas and soybeans by hot air, microwave and combined microwave-hot air drying was investigated. The effect of drying method and drying time on moisture content, shrinkage, water activity, color and texture was measured and optimal drying conditions were estimated.

\section{MATERIALS AND METHODS}

Dry Kabuli chickpeas (Munster Wholefoods; origin: Turkey; harvest year: 2003; product code: 51) and soybeans (Munster Wholefoods; origin: Canada; harvest year: 2003; product code: 34) were purchased from an Irish wholesaler of legumes, and were stored in hermetically sealed bags at room temperature, in a dark room. In preparation for dehydration experiments, 
samples were blanched for 1.5 min by immersion in boiling water, soaked at $40 \pm 0.5 \mathrm{C}$ for $4 \mathrm{~h}$ in a thermostatically controlled water bath, then cooked by immersion in boiling water for $60 \mathrm{~min}$. After cooking, samples were packed in 40-g units and stored at 4C. Storage of cooked chickpeas (cp) and soybeans (sb) was never longer than 4 days before drying experiments. Prior to drying, samples were taken out of storage and allowed to equilibrate with the surrounding air for $16 \mathrm{~h}$. The palisade layer of the soybean seed coat was removed before drying, as it would otherwise crack during drying (this was verified in preliminary drying experiments).

\section{Dehydration Procedure}

A domestic 600-W, 2,450-MHz, combined microwave-hot air oven with 1.33-kW heater (Magnetron, Sanyo 2M218J, Belling Triplette, Belling \& Co., Liverpool, U.K.) and rotating plate was used in all drying experiments (Fig. 1). Microwave power (operating range: $210-560 \mathrm{~W}$ ), air temperature (operating range: $160-250 \mathrm{C}$ ) and processing time were varied using a digital display panel. The power output at each microwave level was measured calorimetrically, by measuring the temperature change of 1-L distilled water during 1-min heating at that level (Cui et al. 2004). Prior to drying experiments, in order to equilibrate the microwave to experimental conditions, a glass beaker contain-

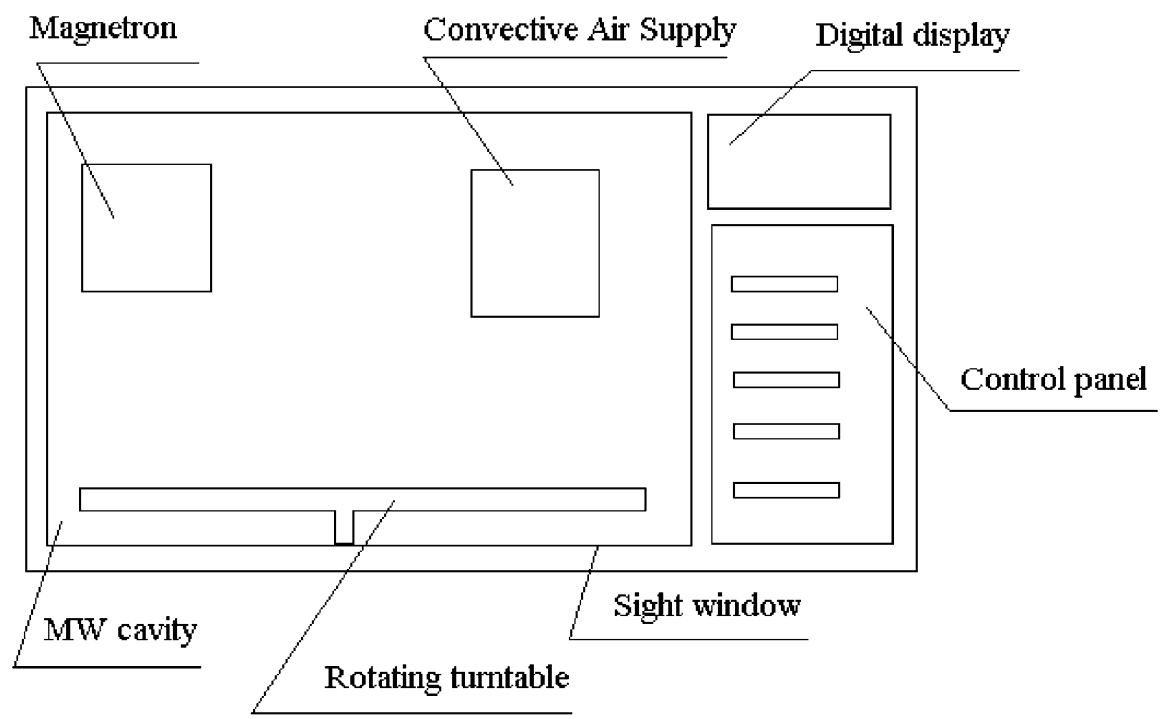

FIG. 1. SCHEMATIC DIAGRAM OF COMBINATION MICROWAVE (MW)-HOT AIR OVEN USED IN DRYING EXPERIMENTS 
TABLE 1.

SAMPLING POINTS (IN MINUTES) FOR CONVECTIVE (Air), MICROWAVE (MW) AND COMBINED (Comb) DEHYDRATION EXPERIMENTS

\begin{tabular}{lcccccc}
\hline \multicolumn{2}{l}{ Chickpeas } & & & \multicolumn{3}{l}{ Soybeans } \\
\cline { 1 - 3 } \cline { 6 - 7 } Air & MW & Comb & & Air & MW & Comb \\
\hline 0 & 0 & 0 & & 0 & 0 & 0 \\
11 & 5 & 1 & & 11 & 5 & 1 \\
21 & 11 & 3 & & 21 & 11 & 3 \\
25 & 17 & 5 & & 32 & 17 & 5 \\
32 & 21 & 7 & & 40 & 21 & 6 \\
40 & 25 & 9 & & 50 & 25 & 9 \\
50 & 32 & 12 & & 60 & 30 & 12 \\
60 & 35 & 15 & & 70 & 35 & 14 \\
70 & & 17 & & 80 & & 15 \\
& & 18 & & & \\
\hline
\end{tabular}

ing 1-L tap water was placed in the microwave, and heated for $30 \mathrm{~min}$ at the required setting. Air velocity was measured using a digital hot wire anemometer (TSI air velocity transducer model no. 8455-300, Buckinghamshire, U.K.) connected to a data logger (Grant Squirrel meter 1000 Series, Cambridgeshire, U.K.) to be $1 \pm 0.05 \mathrm{~m} / \mathrm{s}$.

Three types of drying were studied:

(1) Convective drying (Air). The oven was set to convective mode at $160 \mathrm{C}$ (air velocity $=1 \mathrm{~m} / \mathrm{s})$.

(2) Microwave drying $(M W)$. The oven was set to microwave mode at $210 \mathrm{~W}$ (natural convection [ambient temperature $=23 \mathrm{C}]$ ).

(3) Combined convective-microwave drying (Comb). The oven was set to combination mode, with air temperature set to $160 \mathrm{C}$ (air velocity $=1 \mathrm{~m} / \mathrm{s}$ ), and microwave power at $210 \mathrm{~W}$.

Twenty-gram samples were dried for a specified time, depending on drying method (Table 1), after which they were removed from the oven, and were stored in sealed bags over silica gel in a desiccator in the dark at $24 \pm 1 \mathrm{C}$ for further analysis. Each experiment was performed in triplicate, in a random order, and storage prior to analysis took no longer than 2 days.

\section{Moisture Content Determination}

Moisture content in wet basis (w.b.) was determined before and after drying by the oven method (AOAC 2000). 


\section{Apparent Volume Measurement}

For evaluation of volume during dehydration, the drying experiments (described earlier) were repeated separately. Volume was measured by the method of displacement of water, and measurement time was less than $15 \mathrm{~s}$, to minimize water absorption (Maskan 2001). Bulk shrinkage coefficient $\left(S_{\mathrm{b}}\right)$ was calculated as the ratio of sample volume during drying $(V)$ to initial volume $\left(V_{0}\right)$ (Khraisheh et al. 2004):

$$
S_{\mathrm{b}}=\frac{V}{V_{0}}
$$

\section{Water Activity Measurement}

Water activity $\left(A_{\mathrm{w}}\right)$ of dried samples, after storage in a dessicator containing silica gel for $24-48 \mathrm{~h}$ at $24 \pm 1 \mathrm{C}$, was measured using an Aqualab Series 3 water activity meter (Aqualab, Pullman, WA) for food quality. All water activity measurements were recorded at $24 \pm 1 \mathrm{C}$.

\section{Color Measurement}

The color of crushed and then blended samples during drying was measured using a colorimeter (HunterLab ColorQuest XE, Northants, U.K.). The colorimeter was calibrated with a standard white tile $\left(L^{*}=93.97, a^{*}=-0.88\right.$, $\left.b^{*}=1.21\right)$. The color values were represented on the CIE color scales as $L^{*}$ (lightness/darkness), $a^{*}$ (redness/greenness) and $b^{*}$ (yellowness/blueness). Total color change, $D E^{*}$, was then calculated, from Eq. (3), where $L^{*}{ }_{0}, a^{*}{ }_{0}$ and $b{ }_{0}$ refer to the CIE color values for cooked samples, before drying:

$$
D E^{*}=\sqrt{\left(L^{*}-L_{0}^{*}\right)^{2}+\left(a^{*}-a_{0}^{*}\right)^{2}+\left(b^{*}-b_{0}^{*}\right)^{2}}
$$

\section{Texture Evaluation}

At each sampling point, the texture of 10 samples was evaluated using an Instron Universal Testing Machine (model 4301, Buckinghamshire, U.K.) attached to Series IX data acquisition control and analysis software for materials testing. Each bean was placed on its flattest side and compressed between two metal plates to $10 \%$ of its original thickness. Hardness $(\mathrm{H})$ was defined as the average maximum force required to compress 10 samples, and was calculated as the peak of the force-deformation curve by the Series IX data acquisition control and analysis software package. Force was recorded in $\mathrm{kN}$ per bean. 


\section{RESULTS AND DISCUSSION}

\section{Moisture Content during Drying}

For each of the drying methods examined, moisture content $(M)$ decreased asymptotically with drying time $(t)$ to an equilibrium value very close to zero (Figs. 2 and 3). Drying was slowest for hot air drying, taking 50-60 min to reach equilibrium. Compared with hot air drying, microwave drying alone resulted in up to 50\% reduction in drying time, taking 25-30 min. Overall, drying was fastest in the method of combined microwave-hot air drying, taking just 15-17 min for samples to reach the equilibrium state. Two empirical models, commonly used to model dehydration of foods (Sharma and Prasad 2001; Mwithiga and Olwal 2005; Sacilik and Unal 2005; Simal et al. 2005) known as the Henderson-Pabis model (Eq. 3a) and the Page model (Eq. 3b), were chosen for primary modeling, to investigate which one was best suited to describe the dehydration data:

$$
\begin{gathered}
M=M_{0} e^{-k_{\mathrm{d}} t} \\
M=M_{0} e^{-k_{\mathrm{p}} t_{\mathrm{p}}}
\end{gathered}
$$

Where $M_{0}$ refers to initial moisture content, $k_{\mathrm{d}}$ is the Henderson-Pabis model parameter, and $k_{\mathrm{p}}$ and $n_{\mathrm{p}}$ are Page model parameters. Following nonlinear regression of each model on the chickpea and soybean data sets $(R$
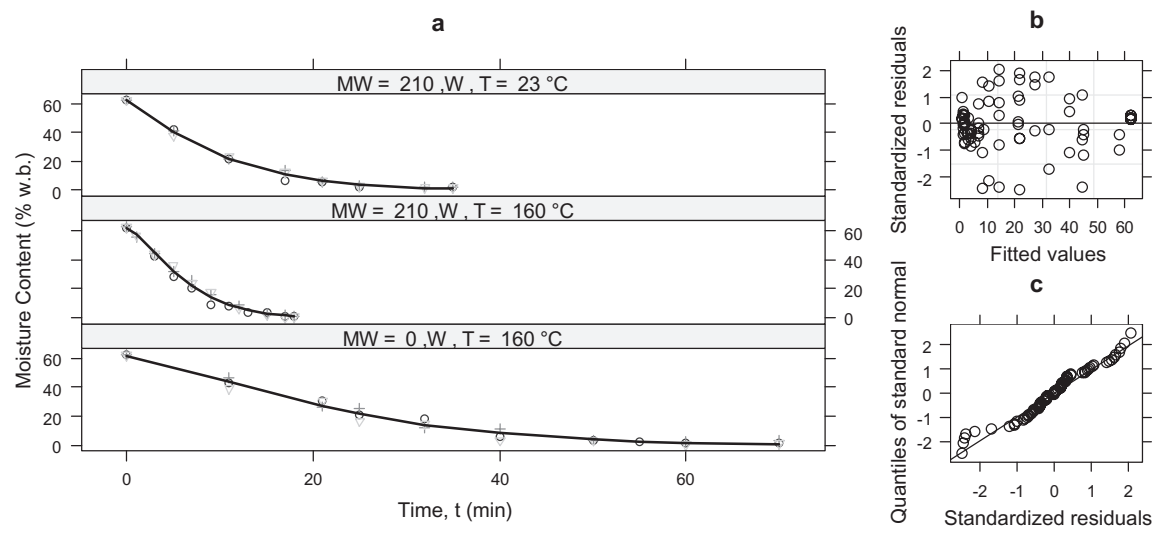

FIG. 2. MOISTURE CONTENT (\% WET BASIS [w.b.]) AS A FUNCTION OF DRYING METHOD AND DRYING TIME FOR COOKED CHICKPEAS

(a) Solid lines indicate predictive plots for nonlinear regression of Eq. (4) on chickpea dehydration data. (b) Residual and (c) quantile-quantile plot for generalized nonlinear regression of Eq. (4) on chickpea dehydration data. MW, microwave. 

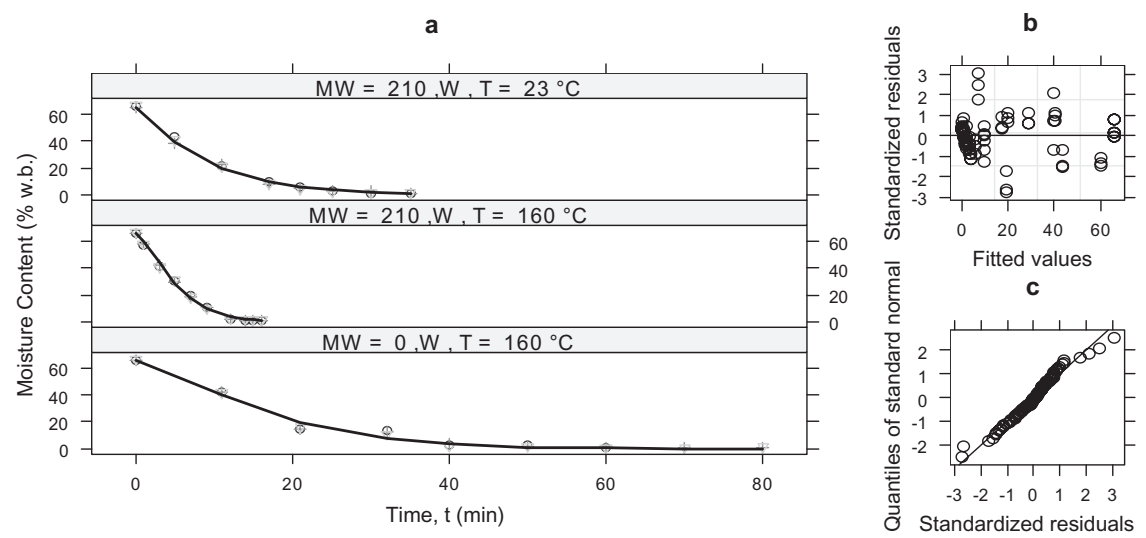

FIG. 3. MOISTURE CONTENT (\% WET BASIS [w.b.]) AS A FUNCTION OF DRYING METHOD AND DRYING TIME FOR COOKED SOYBEANS

(a) Solid lines indicate predictive plots for nonlinear regression of Eq. (4) on soybean dehydration data. (b) Residual and (c) quantile-quantile plot for generalized nonlinear regression of Eq. (4) on soybean dehydration data. MW, microwave.

TABLE 2.

POOLED SE AND AKAIKE INFORMATION CRITERION (AIC) FOR NONLINEAR REGRESSION OF HENDERSON-PABIS MODEL (EQ. 3a) AND PAGE MODEL (EQ. 3b) ON DATA FOR DEHYDRATION OF COOKED CHICKPEAS AND SOYBEANS

\begin{tabular}{lll}
\hline Model & SE & AIC \\
\hline Henderson and Pabis & 3.35 & 825.9 \\
Page & 2.58 & 735.9 \\
\hline
\end{tabular}

Development Core Team 2004), the pooled SE and Akaike information criterion (AIC) were estimated (Table 2). The AIC can be used to compare models in their suitability in describing data sets, taking into account different degrees of freedom. The Page model (Eq. 3b) resulted in both the lowest SE and the lowest AIC for both chickpea and soybean drying data, and was therefore the best suited for modeling of the data.

$M_{0}$ was measured to be $62.5 \pm 0.2$ (\% w.b.) for chickpeas and $66.1 \pm 0.8$ (\% w.b.) for soybeans. Page constants $k_{\mathrm{p}}$ and $n_{\mathrm{p}}$ were estimated for each drying method by nonlinear regression of Eq. (3b) on the data (Table 3). Page constant $k_{\mathrm{p}}$ was significantly $(P<0.05)$ lower for convective drying than for combined or microwave drying, and Page constant $n_{\mathrm{p}}$ was significantly lower for microwave drying $(P<0.05)$ than that for combined or convective drying 
TABLE 3.

PAGE CONSTANTS FOR COOKED CHICKPEAS AND SOYBEANS UNDERGOING CONVECTIVE, MICROWAVE AND COMBINED MICROWAVE-CONVECTIVE DRYING

\begin{tabular}{lllll}
\hline Sample & Drying method & Page constant, $k_{\mathrm{p}}(/ \mathrm{min})$ & Page constant $n_{\mathrm{p}}$ & $k_{\mathrm{p}} \times n_{\mathrm{p}}(/ \mathrm{min})$ \\
\hline Chickpeas & Convective & $0.012 \mathrm{a}$ & $1.39 \mathrm{a}$ & $0.02 \mathrm{a}$ \\
& Microwave & $0.067 \mathrm{~b}$ & $1.17 \mathrm{~b}$ & $0.08 \mathrm{~b}$ \\
\multirow{5}{*}{ Soybeans } & Combined & $0.071 \mathrm{~b}$ & $1.38 \mathrm{a}$ & $0.10 \mathrm{c}$ \\
& Convective & $0.018 \mathrm{a}$ & $1.31 \mathrm{a}$ & $0.02 \mathrm{a}$ \\
& Microwave & $0.068 \mathrm{~b}$ & $1.17 \mathrm{~b}$ & $0.08 \mathrm{~b}$ \\
& Combined & $0.082 \mathrm{~b}$ & $1.37 \mathrm{a}$ & $0.11 \mathrm{c}$ \\
\hline
\end{tabular}

Values within a column sharing the same letter are not significantly different.

TABLE 4.

ESTIMATED REGRESSION PARAMETERS FROM NONLINEAR REGRESSION OF EQ. (4) ON COOKED CHICKPEA AND SOYBEAN DEHYDRATION DATA

\begin{tabular}{llc}
\hline & Chickpeas (AIC =358.5) & Soybeans (AIC =330.98) \\
\hline$M_{0}(\%$ w.b. $)$ & $62.03 \pm 0.67$ & $65.53 \pm 0.59$ \\
$k \mathrm{p}_{1}(/ \mathrm{min})$ & $0.070 \pm 0.006$ & $0.087 \pm 0.006$ \\
$k \mathrm{p}_{2}(/ \mathrm{min})$ & $0.058 \pm 0.005$ & $0.070 \pm 0.005$ \\
$n \mathrm{p}_{1}$ & $1.39 \pm 0.05$ & $1.40 \pm 0.04$ \\
$n \mathrm{p}_{2}$ & $0.25 \pm 0.02$ & $0.31 \pm 0.02$ \\
\hline
\end{tabular}

AIC, Akaike information criterion; $k \mathrm{p}_{1}, k \mathrm{p}_{2}, n \mathrm{p}_{1}, n \mathrm{p}_{2}$, page model constants; $M_{0}$, initial moisture content; w.b., wet basis.

(Table 3). The product of $k_{\mathrm{p}}$ and $n_{\mathrm{p}}$, which is related to the dehydration rate, was significantly $(P<0.05)$ greater for combined drying than either microwave or convective drying, and was significantly $(P<0.05)$ greater for microwave than for convective drying, for both chickpeas and soybeans (Table 3). The following model was proposed to describe $M$ for both chickpeas and soybeans as a function of drying time and drying method:

$$
M=M_{0} e^{-\left(k_{\mathrm{p} 1}-I_{T} * k_{\mathrm{p} 2}\right) t^{n_{\mathrm{p} 1}-I_{\mathrm{MW}} * p_{\mathrm{p} 2}}}
$$

where $I_{T}=1$ for convective drying, and zero otherwise, $I_{\mathrm{MW}}=1$ for microwave drying and zero otherwise, and $k_{\mathrm{p} 1}, k_{\mathrm{p} 2}, n_{\mathrm{p} 1}$ and $n_{\mathrm{p} 2}$ are constants. Equation (4) was regressed on each of the data sets, and the model parameters were estimated (Table 4). Predictive plots were generated from the model, which adequately described the drying data (Figs. $2 \mathrm{a}$ and $3 \mathrm{a}$ ). The standardized residual plots (Figs. 2b and 3b) for Eq. (4) regressed on the chickpea and soybean drying data showed that most residuals were within two standardized residuals, and the quantile-quantile plots (Figs. $2 \mathrm{c}$ and $3 \mathrm{c}$ ) were close to linear, indicating reasonable model fit. 


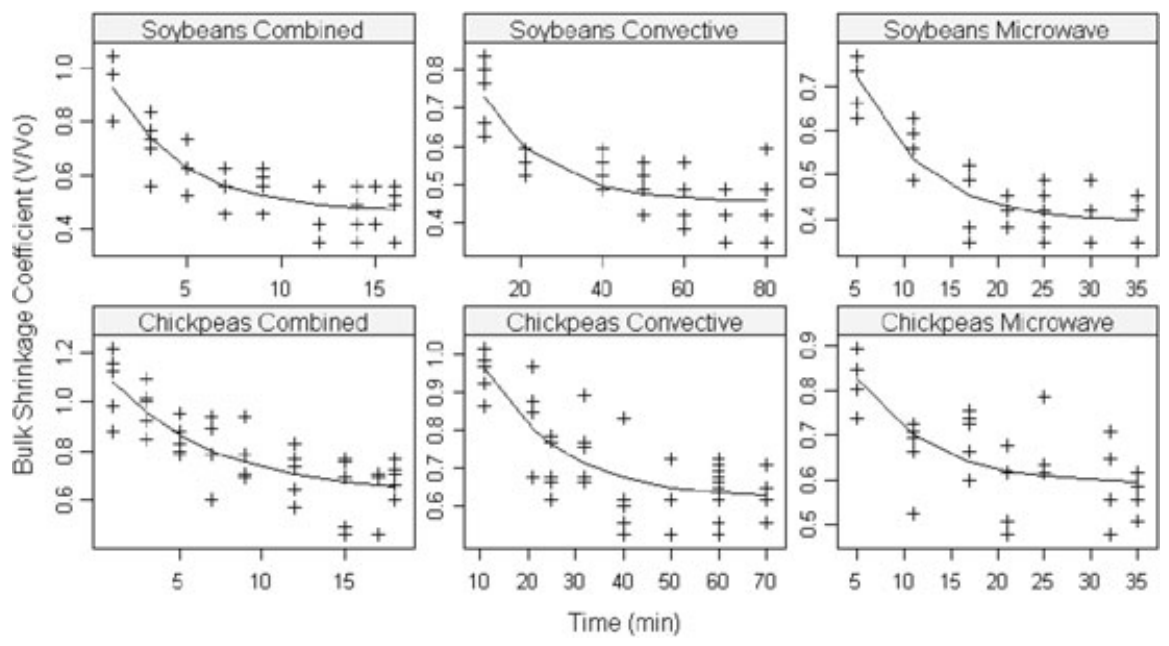

FIG. 4. BULK SHRINKAGE COEFFICIENT AS A FUNCTION OF DRYING METHOD AND DRYING TIME FOR DEHYDRATION OF COOKED CHICKPEAS AND SOYBEANS Solid lines indicate predictive plots for nonlinear regression of Eq. (5) on data.

\section{Apparent Volume Change during Drying}

During drying, moisture is removed from the food sample, causing subsequent decreases in volume. Soybeans shrank during drying, to reach a final apparent volume less than $50 \%$ of their original apparent volume, corresponding to a bulk shrinkage coefficient value of $0.46 \pm 0.04$ (Fig. 4). Chickpeas shrank to a lesser extent, reaching a final apparent volume of around $60 \%$ of their original apparent volume, corresponding to a bulk shrinkage coefficient value of $0.63 \pm 0.07$ (Fig. 4). For each of the drying methods examined, the bulk shrinkage coefficient, $S_{\mathrm{b}}$, decreased exponentially with drying time to a constant value (Fig. 4), and, in the same fashion as drying, the following first-order asymptotic model was chosen to describe the shrinkage kinetics:

$$
S_{\mathrm{b}}=S_{\mathrm{bf}}+\left(S_{\mathrm{b} 0}-S_{\mathrm{bf}}\right) e^{-k_{\mathrm{s}} t}
$$

where $S_{\mathrm{b} 0}$ and $S_{\mathrm{bf}}$ refer to bulk shrinkage coefficient at the beginning and end of drying, respectively, and $k_{\mathrm{s}}$ refers to the bulk shrinkage rate constant. $k_{\mathrm{s}}$ was estimated by nonlinear regression of Eq. (5) on the data (Table 5). For both chickpeas and soybeans, $k_{\mathrm{s}}$ was greatest for combination drying $\left(k_{\text {s_cp_Comb }_{-}}=0.16 \pm 0.05, k_{\text {s_sb_Comb }_{-}}=0.27 \pm 0.06\right)$, and lowest for hot air drying $\left(k_{\text {s_cp_Air }}=0.06 \pm 0.02, k_{\text {s_sb_Air }}=0.07 \pm 0.03\right)$. Microwave drying resulted in an intermediate $k_{\mathrm{s}}$ value $\left(k_{\mathrm{s}_{-} \mathrm{cp} \_\mathrm{MW}}=0.13 \pm 0.07, k_{\mathrm{s}_{\mathrm{S}} \_\mathrm{MW}}=0.14 \pm 0.05\right)$. 
TABLE 5 .

FINAL BULK SHRINKAGE COEFFICIENT $\left(S_{\mathrm{bf}}\right)$, SHRINKAGE RATE CONSTANT $\left(k_{\mathrm{s}}\right)$, AND TIME AT WHICH CHANGES IN $S_{\mathrm{b}}$ BECAME INSIGNIFICANT $\left(t_{\mathrm{eq}}\right)$ FOR COOKED CHICKPEAS AND SOYBEANS UNDERGOING CONVECTIVE, MICROWAVE AND COMBINED MICROWAVE-CONVECTIVE DRYING

\begin{tabular}{llllr}
\hline Sample & Drying method & $S_{\text {bf }} \pm \mathrm{SE}$ & $k_{\mathrm{s}} \pm \mathrm{SE}$ & $t_{\mathrm{eq}}(\mathrm{min})$ \\
\hline Chickpeas & Combined & $0.69 \pm 0.06$ & $0.16 \pm 0.05$ & 11 \\
& Microwave & $0.56 \pm 0.04$ & $0.13 \pm 0.07$ & 15 \\
\multirow{3}{*}{ Soybeans } & Convective & $0.63 \pm 0.06$ & $0.06 \pm 0.02$ & 39 \\
& Combined & $0.50 \pm 0.09$ & $0.27 \pm 0.06$ & 9 \\
& Microwave & $0.41 \pm 0.04$ & $0.14 \pm 0.05$ & 17 \\
& Convective & $0.47 \pm 0.09$ & $0.07 \pm 0.03$ & 35 \\
\hline
\end{tabular}

This result was expected, as combined drying resulted in the fastest drying, and therefore should result in the fastest shrinkage rates. The dry product apparent volume, represented by $S_{\mathrm{bf}}$, was greatest for combination-dried samples $\left(S_{\text {bf_cp_Comb }}=0.69 \pm 0.06, S_{\text {bf_sb_Comb }}=0.50 \pm 0.09\right)$, and smallest for microwave-dried samples $\left(S_{\text {bf_cp_Mw }}=0.56 \pm 0.04, S_{\text {bf_sb_Mw }}=0.41 \pm 0.04\right)$. Convective-dried samples had an intermediate $S_{\text {bf }}$ value ( $S_{\text {bf_cp_Air }}=$ $0.63 \pm 0.06, S_{\text {bf_sb_Air }}=0.47 \pm 0.09$ ). This indicates that most shrinkage occurred for samples that were dried by microwaves only. This was similar to the observation of Maskan (2001), who suggested that rapid shrinkage of kiwis undergoing microwave drying was due to extensive heat generation, accelerating the removal of water during microwave heating. Predictive curves generated from the estimated model parameters (Fig. 4) indicated that Eq. (5) gave a good representation of the average behavior of volume ratio during drying. The drying time after which changes in volume became insignificant $\left(t_{\mathrm{eq}}\right)$ was estimated from Eq. (5) for each of the drying methods examined (Table 5). It was observed that sample volume became fixed at a certain time before the end of the drying process: e.g., chickpea volume was ceased to change significantly $(P>0.05)$ after just $11 \mathrm{~min}$ of combined drying. This was probably due to pulse samples entering the glassy state during drying, after which changes in volume are expected to be minimal.

\section{Water Activity during Drying}

The water activity $\left(A_{\mathrm{w}}\right)$ of dry samples (measured prior to blanching, soaking and cooking) was $0.54 \pm 0.01$ for chickpeas, and $0.67 \pm 0.01$ for soybeans. After soaking and cooking, the water activity of both chickpeas and soybeans was measured to be $0.99 \pm 0.01$. During the early stages of drying, water activity was almost constant (Fig. 5), close to 0.99. Toward the end of drying, at a certain time (dependent on drying method), a rapid decrease in $A_{\mathrm{w}}$ 


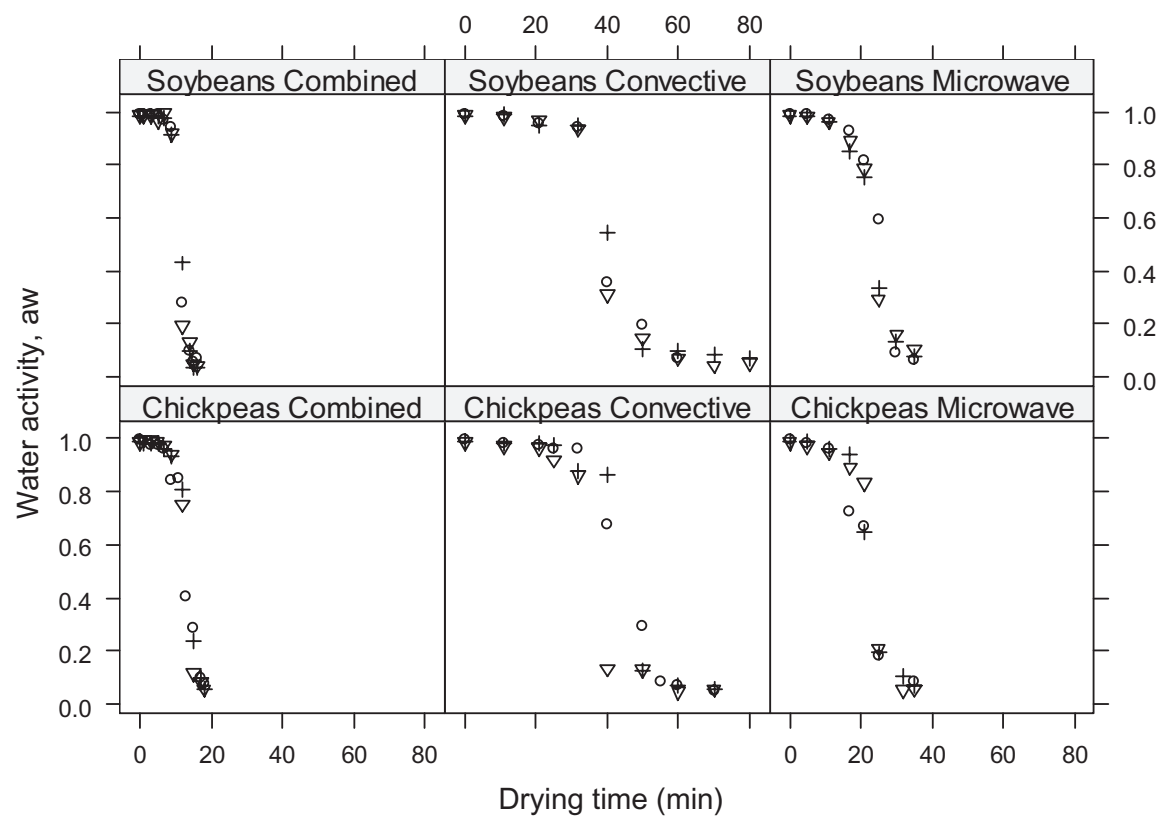

FIG. 5. WATER ACTIVITY $\left(A_{w}\right)$ AS A FUNCTION OF DRYING METHOD AND TIME FOR DEHYDRATION OF COOKED CHICKPEAS AND SOYBEANS

,$+ \bigcirc$ and $\boldsymbol{\nabla}$ refer to first, second and third repetition of each experiment, respectively.

to a value between 0.2 and 0.4 was observed. Further drying caused $A_{\mathrm{w}}$ to decrease slowly to a minimum value less than 0.2 (Fig. 5). The relationship between water activity and moisture content (shown in Fig. 6) appeared to be independent of the drying method.

A number of models, commonly used to describe the relationship between water activity and moisture content, were fitted to the water activity data (Table 6). The pooled SE and AIC were calculated for each model (Table 6). The Peleg model (Eq. 6) resulted in both the lowest SE and AIC values, suggesting (from a purely statistical model selection point of view) that it was best suited to the present study, showing a reasonable fitting of the data without an excessive number of parameters:

$$
M=k_{1} A_{\mathrm{w}}{ }^{n 1}+k_{2} A_{\mathrm{w}}{ }^{n 2}
$$

Model parameters $k_{1}, k_{2}, n_{1}$ and $n_{2}$ were estimated by nonlinear regression of Eq. (6) on the drying data, and are shown in Table 7. Predictive plots were generated from the estimated parameters, and were found to describe the data adequately (Fig. 6). 


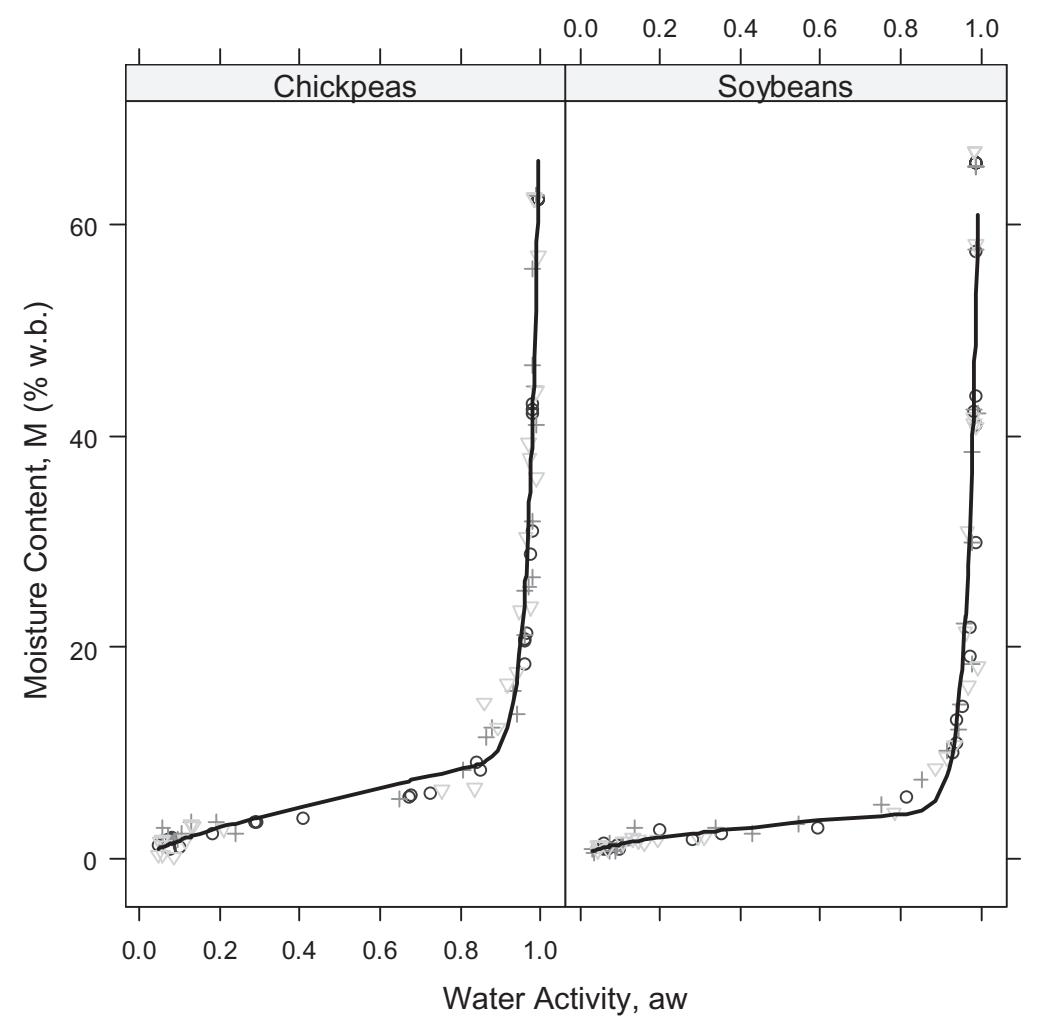

FIG. 6. MOISTURE CONTENT, $M$ (\% WET BASIS [w.b.]) AS FUNCTION OF WATER $\operatorname{ACTIVITY}\left(A_{\mathrm{w}}\right)$

Solid lines indicate predictive plots for nonlinear regression of Eq. (6) on data.

\section{Color Change during Drying}

Before drying, both soybeans (with skin removed) and chickpeas were light yellow in color. This was represented by relatively low redness values $\left(a_{0 \_ \text {cp }} *=8.55 \pm 0.43, a_{0 \_ \text {sb }} *=7.60 \pm 0.07\right)$ compared to high values of lightness $\left(L_{0 \_c p} *=69.88 \pm 0.61, L_{0 \_ \text {sb }} * 68.81 \pm 1.59\right)$ and yellowness $\left(b_{0 \_c p} *=\right.$ $\left.29.20 \pm 0.32, b_{0 \_\mathrm{sb}}{ }^{*}=29.21 \pm 0.59\right)$. Sample color changed during drying, irrespective of the drying method used (Fig. 7). Lightness value, $L^{*}$, decreased during drying (Fig. 7a), indicating that the samples became darker, possibly due to loss of surface water that reduced the luminosity of the sample. In the case of convective drying, the $L^{*}$ value decreased rapidly during the first 40 min of drying, after which time there was little change in the lightness. For both combined and microwave drying, there was a rapid decrease in $L^{*}$ in the 
TABLE 6.

COMPARISON OF MATHEMATICAL MODELS APPLIED TO

WATER ACTIVITY OF COOKED CHICKPEAS AND

SOYBEANS DURING DEHYDRATION, SHOWING POOLED

SE AND AKAIKE INFORMATION CRITERION (AIC)

\begin{tabular}{llll}
\hline Model & Equation & SE & AIC \\
\hline GAB & $M=\frac{M_{\mathrm{o}} \cdot C \cdot K \cdot A_{\mathrm{w}}}{\left(1-K \cdot A_{\mathrm{w}}\right)\left(1-K \cdot A_{\mathrm{w}}+C \cdot A_{\mathrm{w}}\right)}$ & 18.5 & $1,303.9$ \\
Henderson & $M=\left(\frac{\ln \left(1-A_{\mathrm{w}}\right)}{A}\right)^{\frac{1}{B}}$ & 8.6 & $1,136.0$ \\
Hasley & $M=\left(\frac{A}{\ln \left(A_{\mathrm{w}}\right)}\right)^{\frac{1}{B}}$ & 9.1 & $1,156.0$ \\
Smith & $M=A+b \ln \left(1-A_{\mathrm{w}}\right)$ & 10.4 & $1,198.3$ \\
BET & $M=\frac{13.5}{\left(\left(1-A_{\mathrm{w}}\right)+(C-1)\left(1-A_{\mathrm{w}}\right) A_{\mathrm{w}}\right)}$ & $1,290.4$ \\
Peleg & $M=k_{1} A_{\mathrm{w}}{ }^{n 1}+k_{2} A_{\mathrm{w}}{ }^{n 2}$ & 7.9 & $1,111.2$ \\
\hline
\end{tabular}

$M$, moisture content at any time; $M_{0}$, initial moisture content; $A_{\mathrm{w}}$, water activity; $A, b, B, C, K, k_{1}, k_{2}, n 1, n 2=$ constants.

TABLE 7.

ESTIMATED PARAMETERS FOR NONLINEAR REGRESSION

OF PELEG MODEL (EQ. 6) ON WATER ACTIVITY OF COOKED CHICKPEAS AND SOYBEANS DURING DRYING

\begin{tabular}{llc}
\hline Sample & Chickpeas & Soybeans \\
\hline$k_{1}$ & $65.0 \pm 5.1$ & $71.9 \pm 5.7$ \\
$k_{2}$ & $10.0 \pm 3.0$ & $4.7 \pm 3.6$ \\
$n_{1}$ & $36.3 \pm 5.9$ & $35.0 \pm 6.9$ \\
$n_{2}$ & $0.77 \pm 0.45$ & $0.55 \pm 0.66$ \\
\hline
\end{tabular}

$k_{1}, k_{2}, n_{1}, n_{2}$, Peleg model parameters.

early drying stages, followed by a constant phase, after which another rapid decrease in $L^{*}$ was observed. During the early stages of drying, the $b^{*}$ value, representing yellowness, increased slightly to a maximum value (Fig. 7b), after which it decreased, indicating destruction of the yellow pigment. The $a^{*}$ value, representing red color, increased with drying time to an equilibrium value (Fig. 7c).

As water activity decreased from 1 to 0.9 , total color change $\left(D E^{*}\right)$ increased rapidly (Fig. 8), corresponding to the rapid change in moisture content during the early to mid-drying stages (when water activity was almost constant). $D E^{*}$ remained fairly constant while $A_{\mathrm{w}}$ decreased, until reaching a 

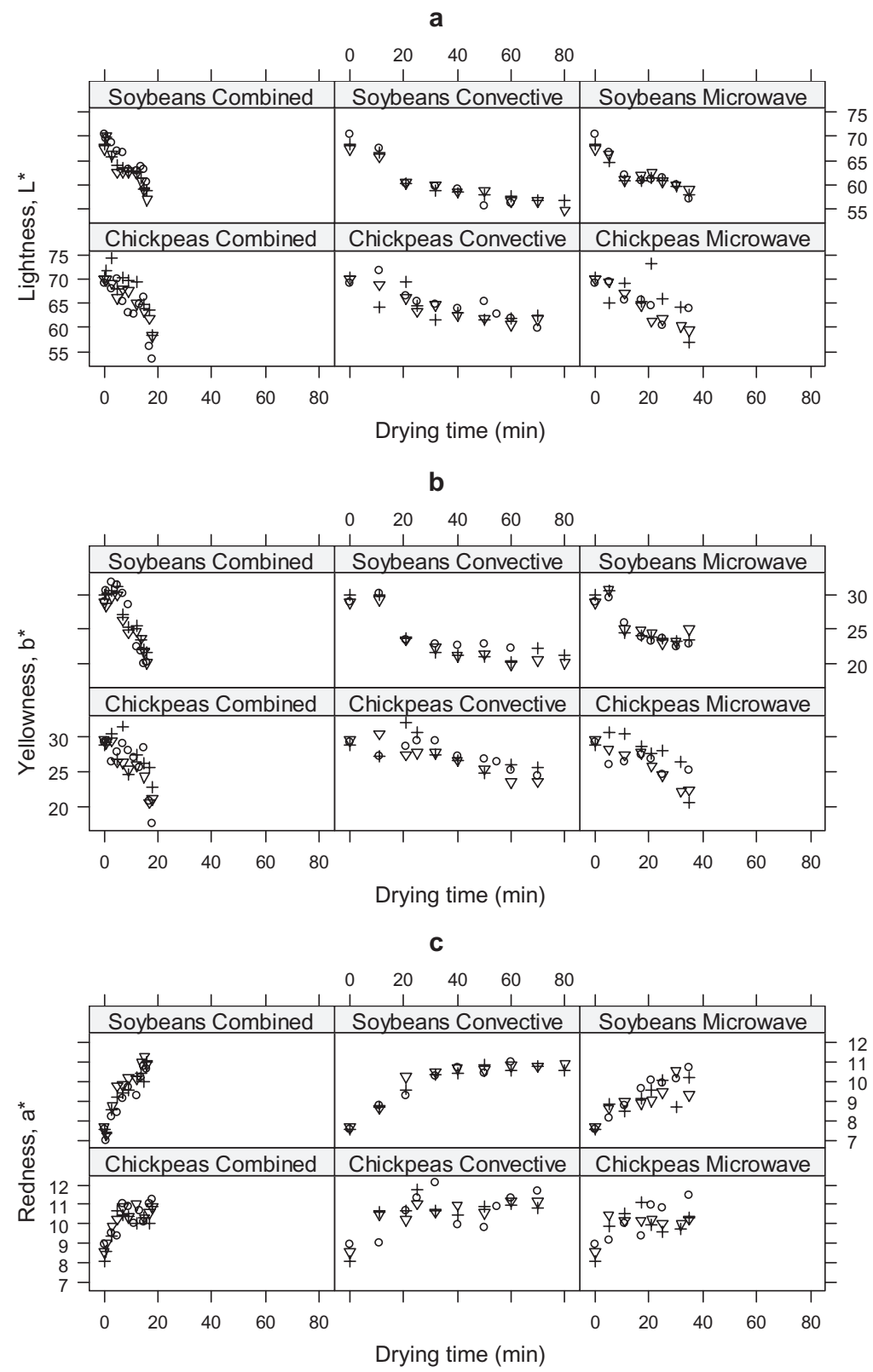

FIG. 7. CIE $L^{*}$ (a), $b^{*}$ (b) AND $a^{*}(\mathrm{c})$ VALUES AS A FUNCTION OF DRYING METHOD AND

TIME FOR DEHYDRATION OF COOKED CHICKPEAS AND SOYBEANS

,$+ \bigcirc$ and $\boldsymbol{\nabla}$ refer to first, second and third repetition of each experiment, respectively. 


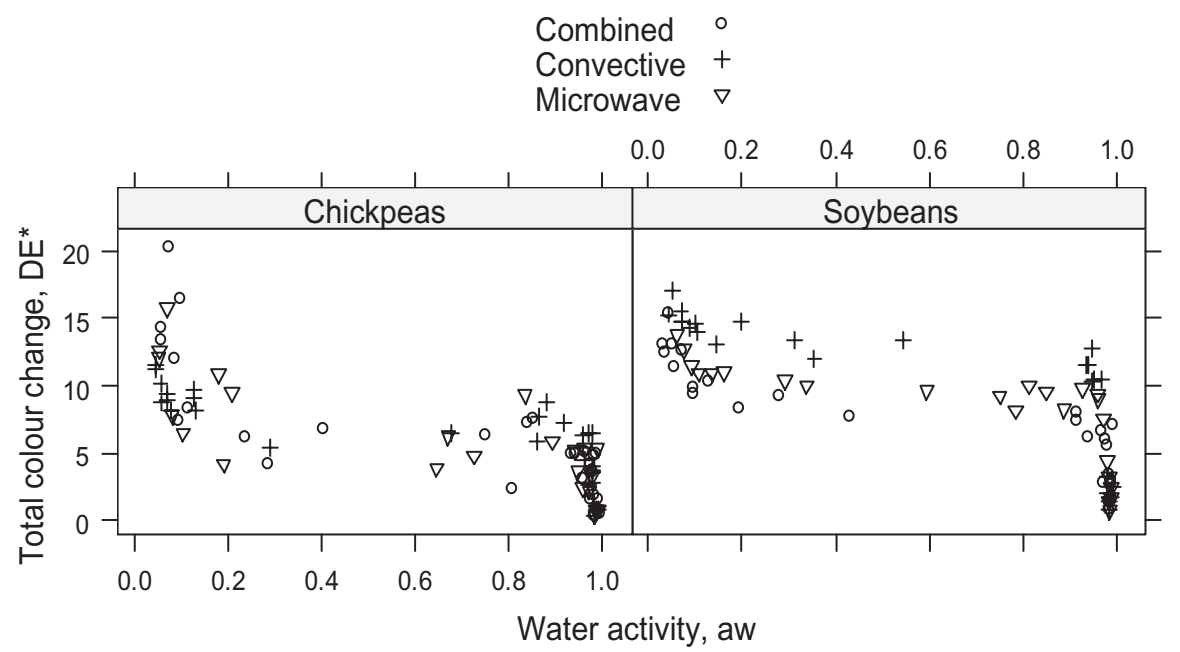

FIG. 8. TOTAL COLOR CHANGE, $D E^{*}$, AS A FUNCTION OF WATER ACTIVITY FOR DEHYDRATION OF COOKED CHICKPEAS AND SOYBEANS

water activity value around less than 0.4 , when a second increase in $D E^{*}$ occurred. At this stage, rapid browning of samples was observed, accelerated by a combination of the high drying temperatures and low water activity. In order to estimate the water activity at which rapid browning occurred, $D E^{*}$ $\left(A_{\mathrm{w}}<0.9\right)$ was fitted to a linear model with break point (Muggeo 2003), and the break $A_{\mathrm{w}}$ was estimated to be $0.27 \pm 0.07$ for chickpeas $(P<0.05)$, and $0.13 \pm 0.04$ for soybeans $(P<0.05)$.

\section{Texture during Drying as a Function of Water Activity}

For each of the drying methods examined, sample hardness initially increased with drying time to a maximum value, after which it decreased rapidly, approaching an equilibrium value (Fig. 9). The initial increase in hardness was due to the toughening of the samples' crust or core because of initial water loss, when water activity was approximately constant. The subsequent rapid decrease in hardness was caused by the creation of a porous network, which affected the ability of the bean structure to support itself. Sample hardness increased as moisture content decreased (Fig. 10), until a critical moisture level (15-20\% for chickpeas, $10-15 \%$ for soybeans) was reached. As moisture content decreased below these levels, a rapid decrease in hardness was observed. The situation is somewhat analogous to the concept of moisture toughening, in which water acts as an antiplasticizer of food at low moisture contents. Antiplasticization peaks in the compressive fracture stress 

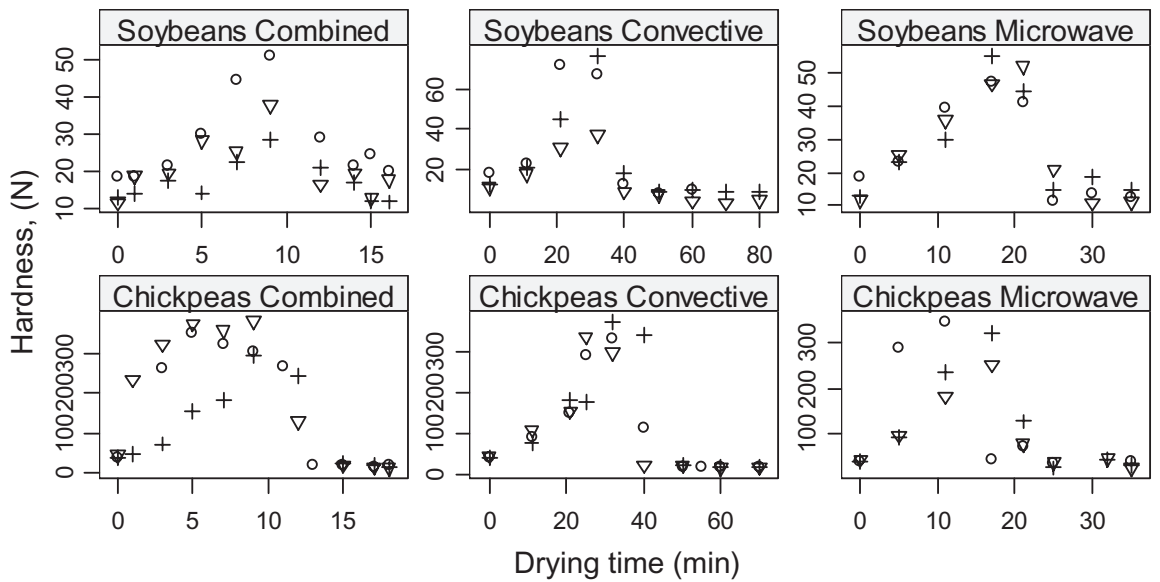

FIG. 9. AVERAGE HARDNESS (N) AS A FUNCTION OF DRYING METHOD AND TIME FOR DEHYDRATION OF COOKED CHICKPEAS AND SOYBEANS

,$+ \bigcirc$ and $\boldsymbol{\nabla}$ refer to first, second and third repetition of each experiment, respectively.
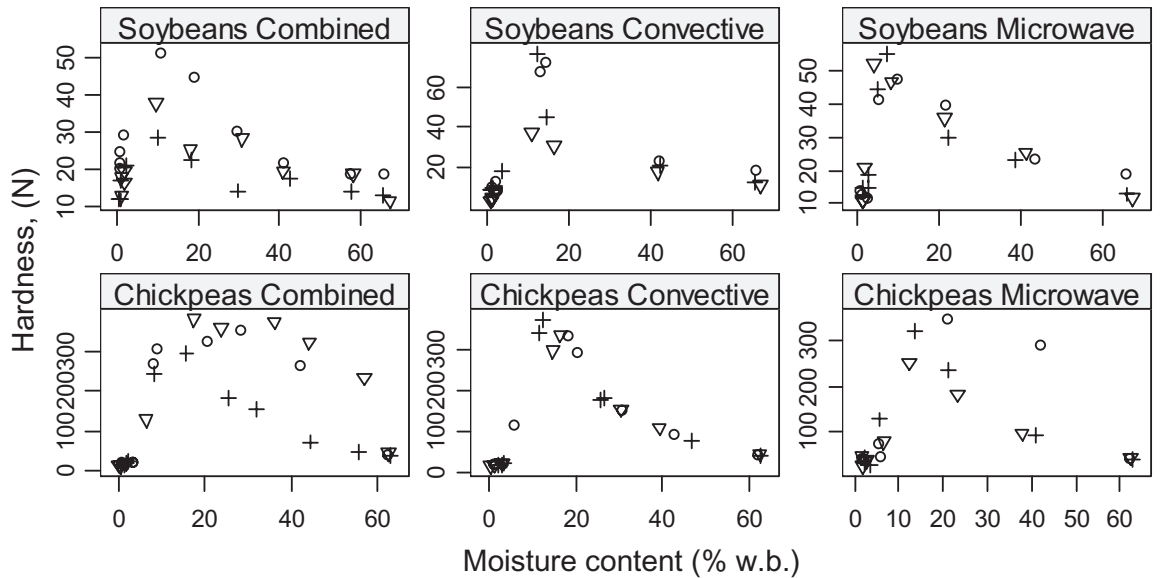

FIG. 10. AVERAGE HARDNESS (N) AS A FUNCTION OF DRYING METHOD AND MOISTURE CONTENT FOR DEHYDRATION OF COOKED CHICKPEAS AND SOYBEANS ,$+ \bigcirc$ and $\boldsymbol{\nabla}$ refer to first, second and third repetition of each experiment, respectively. w.b., wet basis.

of bread have been found at intermediate water contents of 9-12\% (Fontanet et al. 1997), similar to those seen in Fig. 9. However, such antiplasticization peaks were seen during hydration, while the situation presented here is that of rapid dehydration. 


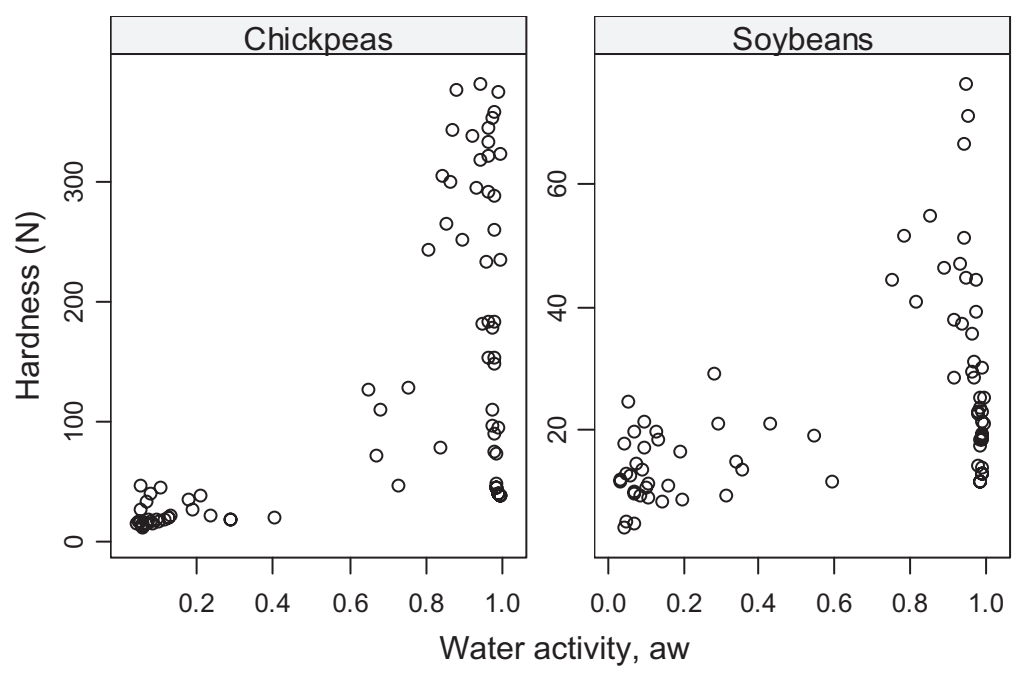

FIG. 11. AVERAGE HARDNESS (N) AS A FUNCTION OF WATER ACTIVITY FOR DEHYDRATION OF COOKED CHICKPEAS AND SOYBEANS

As water activity $\left(A_{\mathrm{w}}\right)$ decreased from 1 to a value of approximately 0.96 , sample hardness increased to a maximum value (Fig. 11). As $A_{\mathrm{w}}$ decreased from 0.96, hardness decreased toward an equilibrium value, not changing much as $A_{\mathrm{w}}$ decreased below 0.4, which is assumed to correspond to the onset of glass transition. In order to estimate the water activity at which hardness $(\mathrm{H})$ reached an equilibrium value, $\mathrm{H}$ for $A_{\mathrm{w}}<0.96$ was fitted to a linear model with break point (Muggeo 2003), and the break $A_{\mathrm{w}}$ was estimated to be $0.40 \pm 0.10$ for chickpeas $(P<0.05)$, and $0.63 \pm 0.15$ for soybeans $(P<0.05)$.

\section{Estimation of Optimal Drying Conditions}

In the previous sections, it was estimated that in order to avoid excessive browning, water activity should not be reduced during drying to a value below $0.27 \pm 0.07$ for chickpeas and $0.13 \pm 0.04$ for soybeans, and that in order to reach glass transition, water activity should be decreased to a value below $0.40 \pm 0.10$ for chickpeas, and below $0.63 \pm 0.15$ for soybeans. In the Introduction section, it was stated that foods dried to a final $A_{\mathrm{w}}$ level between 0.3 and 0.5 should not experience microbial growth, lipid oxidation or browning during storage. Therefore, drying chickpeas and soybeans to a final $A_{\mathrm{w}}$ level of 0.35 would prevent burning, allowing for glass transition, while also ensuring microbial safety, preventing lipid oxidation and browning during storage. Using the Peleg model (Eq. 6), the moisture content corresponding to any 
TABLE 8.

DRYING TIME $\left(t_{M}\right)$ REQUIRED TO REACH A FINAL MOISTURE CONTENT $(M)$ CORRESPONDING TO A WATER ACTIVITY OF 0.35 FOR COOKED CHICKPEAS $\left(t_{M=4.43 \%}\right)$ AND SOYBEANS $\left(t_{M=2.65 \%}\right)$ DURING CONVECTIVE, MICROWAVE AND COMBINED MICROWAVE-CONVECTIVE DEHYDRATION

\begin{tabular}{lll}
\hline Drying method & Chickpeas, $t_{M=4.43 \%}(\min )$ & Soybeans $t_{M=2.65 \%}(\min )$ \\
\hline Convective & 48.4 & 42.2 \\
Microwave & 24.1 & 27.4 \\
Combined & 13.6 & 13.2 \\
\hline
\end{tabular}

particular water activity can be estimated for both cooked chickpeas and cooked soybeans during drying. For chickpeas, $A_{\mathrm{w}}=0.35$ corresponds to a moisture content of $4.43 \%$, while for soybeans, $A_{\mathrm{w}}=0.35$ corresponds to a moisture content of $2.65 \%$. The drying time required by each drying method to reach this moisture content can then be estimated from Eq. (4) (Table 8). Combined drying would yield dehydrated chickpeas and soybeans with suitable water activity $\left(A_{\mathrm{w}}=0.35\right)$ within 14 -min drying, which is more than 1.7 times faster than microwave drying, and more than 3.3 times faster than convective drying.

\section{CONCLUSIONS}

Combining microwave with hot air drying decreased the drying time, and the overall shrinkage encountered during drying, compared with convective drying and microwave drying, for cooked chickpeas and soybeans. Glass transition behavior during drying was evidenced by shrinkage and texture behavior. Water activity was reduced during drying, for each of the methods examined. However, the onset of burning occurred when samples were dried to very low water activities ( 0.27 for chickpeas and 0.13 for soybeans), because of the high temperatures encountered in the processing. Drying chickpeas and soybeans to a water activity of 0.35 would produce glassy dry products without severe discoloration. Results indicated that combined microwave-convective drying of cooked chickpeas and soybeans is viable, producing shelf stable products within relatively short processing times.

\section{ACKNOWLEDGMENT}

The first author would like to acknowledge funding from the Irish government under Strand I of the National Development Plan. 


\section{REFERENCES}

AOAC. 2000. Official Methods of Analysis, 17th Ed., Association of Official Analytical Chemists, Gaithersburg, MD.

BERTELI, M.N. and MARSAIOLI, A. 2005. Evaluation of short cut pasta air dehydration assisted by microwaves as compared to the conventional drying process. J. Food Eng. 68, 175-183.

BILBAO-SAINZ, C., ANDRES, A. and FITO, P. 2005. Hydration kinetics of dried apple as affected by drying conditions. J. Food Eng. 68, 369-376.

CUI, Z.-W., XU, S.-Y. and SUN, D.-W. 2004. Microwave-vacuum drying kinetics of carrot slices. J. Food Eng. 65, 157-164.

EICHNER, K., LAIBLE, R. and WOLF, W. 1985. The influence of water content and temperature on the formation of Maillard reaction intermediates during drying of plant products. In Properties of Water in Foods (D. Simatos and J.L. Moulton, eds.) pp. 191-210, Martinus Nijhoff Pub., Dordrecht, the Netherlands.

FONTANET, S., DAVIDOU, S., DACREMONT, C. and LE MESTE, M. 1997. Effect of water on the mechanical behaviour or extruded flat bread. J. Cereal Sci. 25, 303-311.

FUNEBO, T. and OHLSSON, T. 1998. Microwave-assisted air dehydration of apple and mushroom. J. Food Eng. 38, 252-267.

GOWEN, A., ABU-GHANNAM, N., FRIAS, J. and OLIVEIRA, J. 2006. Optimisation of dehydration and rehydration properties of cooked chickpeas (Cicer arietinum L.) undergoing microwave-hot air combination drying. Trends Food Sci. Technol. 17, 177-183.

KASAPIS, S. 2006. Definition and applications of the network glass transition temperature. Food Hydrocolloids 20, 218-228.

KHRAISHEH, M.A.M., MCMINN, W.A.M. and MAGEE, T.R.A. 2004. Quality and structural changes in starchy foods during microwave and convective drying. Food Res. Int. 37, 497-503.

KROKIDA, M.K., KARATHANOS, V.T., MAROULIS, Z.B. and MARINOS-KOURIS, D. 2003. Drying kinetics of some vegetables. J. Food Eng. 59, 391-403.

LABUZA, T.P. 1980. The effect of water activity on reaction kinetics of food deterioration. Food Technol. 34, 36-42.

LABUZA, T.P. and SALTMARCH, M. 1981. The nonenzymatic browning reaction as affected by water activity in foods. In Water Activity: Influences on Food Quality (L.B. Rockland and G.F. Stewart, eds.) p. 605, Academic Press, New York, NY.

LING, H.-I., BIRCH, J. and LIM, M. 2005. The glass transition approach to determination of drying protocols for colour stability in dehydrated pear slices. Int. J. Food Sci. Technol. 40, 921. 
MASKAN, M. 2000. Microwave/air and microwave finish drying of banana. J. Food Eng. 44, 71-78.

MASKAN, M. 2001. Drying, shrinkage and rehydration characteristics of kiwifruits during hot air and microwave drying. J. Food Eng. 48, 177182.

MUGGEO, V.M. 2003. Estimating regression models with unknown breakpoints. Stat. Med. 22, 3055-3071.

MWITHIGA, G. and OLWAL, J.O. 2005. The drying kinetics of kale (Brassica oleracea) in a convective hot air dryer. J. Food Eng. 71, 373-378.

NIJHUIS, H.H., TORRINGA, H.M., MURESAN, S., YUKSEL, D., LEGUIJT, C. and KLOEK, W. 1998. Approaches to improving the quality of dried fruit and vegetables. Trends Food Sci. Technol. 9, 13-20.

PRIESTLY, D.A., WERNER, B.G. and LEOPOLD, A.C. 1985. The susceptibility of soybean seed lipids to artificially-enhanced atmospheric oxidation. J. Exp. Bot. 36, 668-674.

R DEVELOPMENT CORE TEAM. 2004. R: A Language and Environment for Statistical Computing, R Foundation for Statistical Computing, Vienna, Austria. http://www.R-project.org (accessed March 20, 2005).

RATTI, C. 2001. Hot air and freeze-drying of high-value foods: A review. J. Food Eng. 49, 311-319.

SABLANI, S.S., KASAPIS, S. and RAHMAN, M.S. 2007. Evaluating water activity and glass transition concepts for food stability. J. Food Eng. 78, 266-271.

SACILIK, K. and UNAL, G. 2005. Dehydration characteristics of kastamonu garlic slices. Biosyst. Eng. 92, 207-215.

SCHNEIDER, A.V. 2002. Overview of the market and consumption of pulses in Europe. Br. J. Nutr. 88, S243-S250.

SHARMA, G.P. and PRASAD, S. 2001. Drying of garlic (Allium sativum) cloves by microwave-hot air combination. J. Food Eng. 50, 99-105.

SIMAL, S., FEMENIA, A., GARAU, M.C. and ROSSELLÓ, C. 2005. Use of exponential, Page's and diffusional models to simulate the drying kinetics of kiwi fruit. J. Food Eng. 66, 323-328.

TROLLER, J. 1989. Water activity and food quality. In Water and Food Quality (T. Hardman, ed.) pp. 1-31, Elsevier Applied Science, London, England.

VEGA-MERCADO, H., GÓNGORA-NIETO, M.M. and BARBOSACÁNOVAS, G.V. 2001. Advances in dehydration of foods. J. Food Eng. 49, 271-289. 